\title{
Analyses of the Calendaring Process for Performance Optimization of Li-Ion Battery Cathode
}

\author{
Charles F. Oladimeji, Pedro L. Moss, and Mark H. Weatherspoon \\ Department of Electrical and Computer Engineering, Florida A\&M University and Florida State University, \\ Tallahassee, FL 32310, USA \\ Correspondence should be addressed to Pedro L. Moss; plm1735@my.fsu.edu
}

Received 3 April 2016; Revised 23 July 2016; Accepted 25 July 2016

Academic Editor: Zetian Tao

Copyright (C) 2016 Charles F. Oladimeji et al. This is an open access article distributed under the Creative Commons Attribution License, which permits unrestricted use, distribution, and reproduction in any medium, provided the original work is properly cited.

\begin{abstract}
Olivine structure $\mathrm{LiFePO}_{4}$ (LFP) was synthesized via solid state processes, using $\mathrm{Li}_{2} \mathrm{CO}_{3}, \mathrm{NH}_{4} \mathrm{H}_{2} \mathrm{PO}_{4}$, and $\mathrm{FeC} \mathrm{O}_{4} \cdot \mathrm{H}_{2} \mathrm{O}$ and $\mathrm{C}_{12} \mathrm{H}_{22} \mathrm{O}_{11}$ as precursor materials. The effects of calendaring are analyzed in terms of electrochemical performance, cycle life, surface morphology, and ac impedance analysis. The resulting LFP electrode was divided into calendared and uncalendared samples. Under electrochemical impedance testing, the calendared and uncalendared electrodes exhibited a charge transfer resistance of $157.8 \Omega$ and $182.4 \Omega$, respectively. The calendared electrode also exhibited a higher discharge capacity of about $130 \mathrm{mAh} / \mathrm{g}$ at $0.1 \mathrm{C}$ compared to a discharge capacity of $120 \mathrm{mAh} / \mathrm{g}$ at $0.1 \mathrm{C}$ for the uncalendared electrode.
\end{abstract}

\section{Introduction}

Lithium-ion batteries have an unmatchable combination of high-power and high-energy density and are expected to play a prominent role as larger-scale energy storage for renewable energy sources (e.g., wind, solar, and geothermal), aerospace application, grid-electric storage, and the main energy supply for hybrid/electric vehicles. The main advantage of lithiumion batteries includes its high gravimetric and volumetric energy density compared to conventional rechargeable batteries. Compared to alternative battery technologies, Li-ion batteries provide the best energy-to-weight ratios, exhibit no memory affects, and have a low self-discharge rate when not in use. Since the introduction of lithium iron phosphate as cathode material for lithium-ion batteries, lots of effort has gone into improving the electrochemical performance of this material. Over the years many techniques such as carbothermal reduction [1], doping [2], particle size reduction [3,4], and mechanochemical activation [5] have been developed to enhance the electrochemical performance of this cathode material. Synthesis methods such as polyol [6], spray pyrolysis [7], solvothermal [8], and sol gel [9] have also been successfully used to synthesize electrodes with very good performance at high rates due to high process and parameter control. The problem with these synthesis methods is scalability, since the lab scale production obtained using these techniques is not viable for commercial scale production. Solid state synthesis, a common synthesis method for preparing ceramics adopted to make battery materials, involves heating the precursor at temperatures high enough for reactions to occur. The advantage of this method is its simplicity and ease of scalability for commercial production [10].

Electron transport in lithium-ion battery structure is a key factor in the overall battery performance; therefore the calendaring of the electrodes has become an important step in the battery fabrication process and is carried out after the coating and drying stage of fabrication, Figure 1. In this process the electrodes are compacted to improve the volumetric energy density and rate performance of the electrodes. Besides reduction of volumetric density, calendaring alters other physical properties of the electrode including the electrode porosity [11], the lithium diffusion length [12], and interparticle contact [13]. Several works have studied the effects of electrode thickness and density for unpressed and pressed electrodes, on high-cycling and high-rate performance [14-17]. These results indicate that the pressing of the electrodes increases the capacity retention at high rate, 


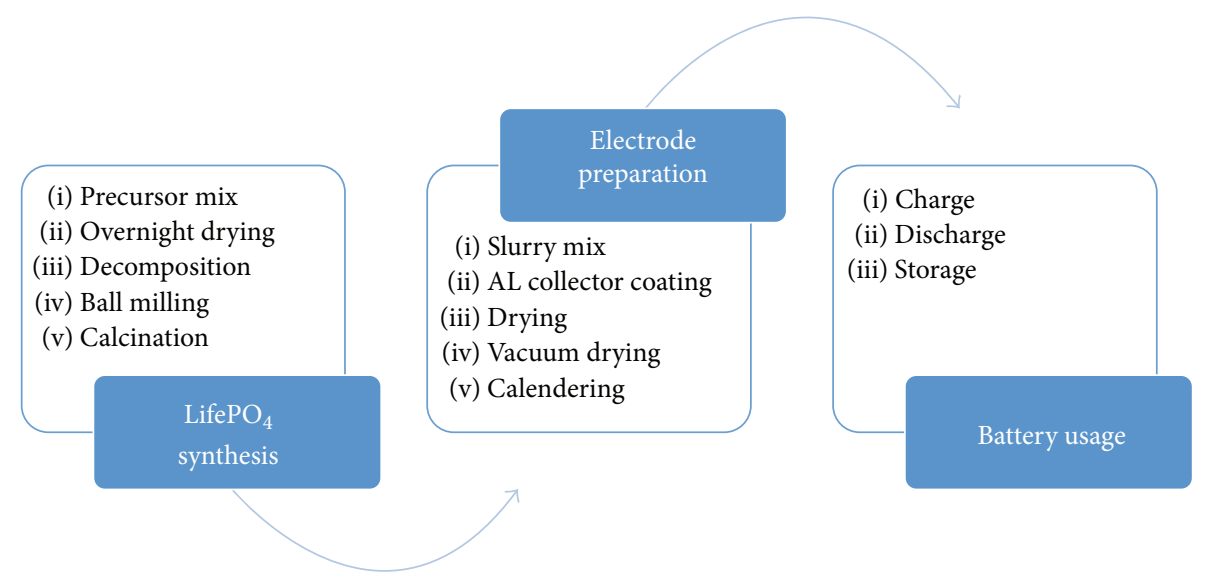

FIGURE 1: Solid state calcination process.

reduces the contact resistance, and results in a significant improvement to the cycling performance when compared to the unpressed electrodes.

In this paper we analyze the role of compression of the positive electrode and its effects on performance and which interphase, electrode/electrolyte interface, and electrode/current collector interface contributes to enhancing electrode performance. Cyclic voltammetry, surface morphology, capacity fade, electrochemical impedance behavior, and rate capability are analyzed for both calendared and uncalendared electrodes.

\section{Experimental}

Stoichiometric amounts of precursor materials (lithium carbonate $\left(\mathrm{Li}_{2} \mathrm{CO}_{3}\right)$, iron oxalate hydrate $\left(\mathrm{FeC}_{2} \mathrm{O}_{4} \cdot 2 \mathrm{H}_{2} \mathrm{O}\right)$, ammonium phosphate monobasic $\left(\mathrm{NH}_{4} \mathrm{H}_{2} \mathrm{PO}_{4}\right)$, and sucrose $\left.\left(\mathrm{C}_{12} \mathrm{H}_{22} \mathrm{O}_{11}\right)\right)$ were mixed together with acetone in a ball mill at 350 RPM for 5 hours to form a homogenous slurry. The slurry was dried at $60^{\circ} \mathrm{C}$, and after drying it was decomposed at $350^{\circ} \mathrm{C}$ for 10 hours in an argon/hydrogen environment to decompose the carbonate, oxalate, and ammonium. The decomposed precursor was then ball milled at $500 \mathrm{RPM}$ for 5 hours and then calcined at $650^{\circ} \mathrm{C}$ in a tube furnace for 12 hours.

After synthesis of C-LiFePO , LFP Powder, carbon black, and PVDF binder were mixed at 85:7:8 percentage mass ratio overnight using a magnetic stirrer. The slurry was coated on an aluminum foil ( $20 \mu \mathrm{m}$ thickness) using the doctor blade method and then dried under vacuum overnight. The electrode sheet was cut in half and labelled Sample A and Sample B. Sample A was pressed to a density of $2.63 \mathrm{~g} \mathrm{~cm}^{-3}$ and Sample B was unpressed and had a density of $0.916 \mathrm{~g} \mathrm{~cm}^{-3}$. The density of the electrode is defined by volumetric mass density of the electrode material (mixture of active material, binder, and conductive agent). Taking the thickness $\delta_{E}$ and the mass loading $m_{L}$ of the composite electrode, the coating layer density was calculated from the equation given below:

$$
\rho=\frac{m_{L}}{\delta_{E}}\left(\mathrm{~g} / \mathrm{cm}^{3}\right)
$$

The various electrodes were then punch and assembled to make half cells with $\mathrm{LiFePO}_{4} / \mathrm{C}$, electrolyte from BASF containing $1 \mathrm{M} \mathrm{LiFP}_{6} \mathrm{EC}: \mathrm{EMC} 1: 2+2 \% \mathrm{VC}$ and lithium metal as positive electrode.

SEM was done using the JEOL JSM-7410F machine. Since the electrode was already carbon-coated there was no need for further sputter coating to improve the conductivity of the material. Cyclic voltammetry was measured between $2.5 \mathrm{~V}$ and 4.2 V using the Solartron Mobrey SI 1280B electrochemical measurement unit. The MTIXL Galvanostat was used to charge and discharge the battery using the constant current constant voltage (CC-CV) routine between $3 \mathrm{~V}$ and $3.65 \mathrm{~V}$. EIS measurements were taken using the Gamry Instrument Reference 3000 at room temperature.

\section{Results and Discussion}

3.1. Surface Morphology. The calendared electrode when viewed with the bare eye looked shiny compared to the uncalendared electrode that appeared matte black. SEM images were taken for both the uncalendared and the calendared electrode and are shown in Figure 2. SEM micrographs of magnification at $\times 1000, \times 5000$, and $\times 10000$ are presented, and the images of these electrodes show very porous structures. However, the SEM images of the calendared electrode show a reduction in porosity after electrode densification.

3.2. Cyclic Voltammetry (CV). CV in Figure 3 shows similar anodic and cathodic peaks for both batteries, and the similarity of $\mathrm{CV}$ for both electrodes indicates the behavior of the electrode is similar which is expected since the fabrication processes were exactly the same for both electrodes until the calendaring process. Multiple cycles were run, and all cycles exhibited similar behavior and good reversibility as shown in Figure 3. CV measurements were taken at a scan rate of 

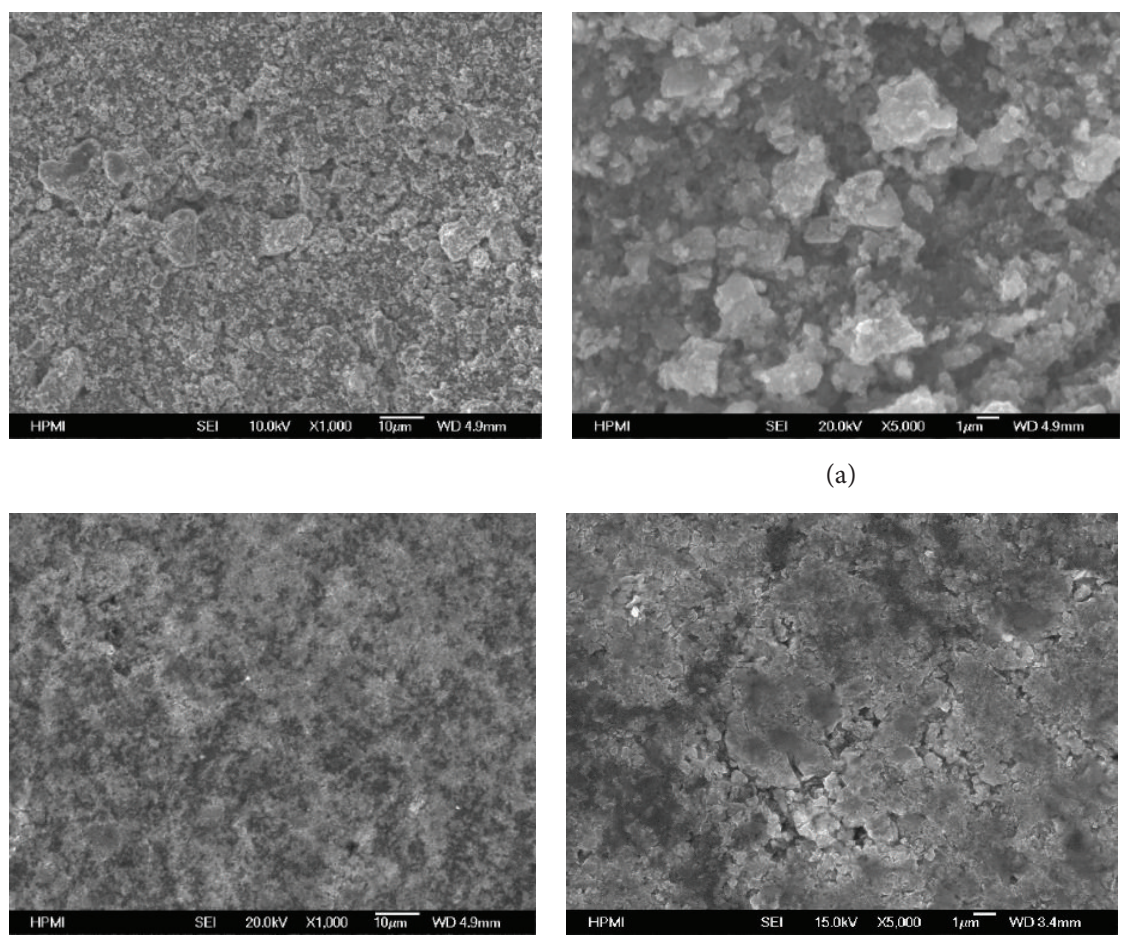

(b)

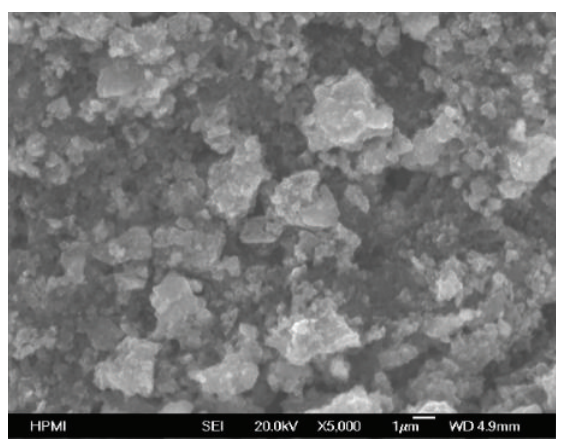

(a)
FIGURE 2: SEM images of (a) uncalendared electrode and (b) calendared electrode.

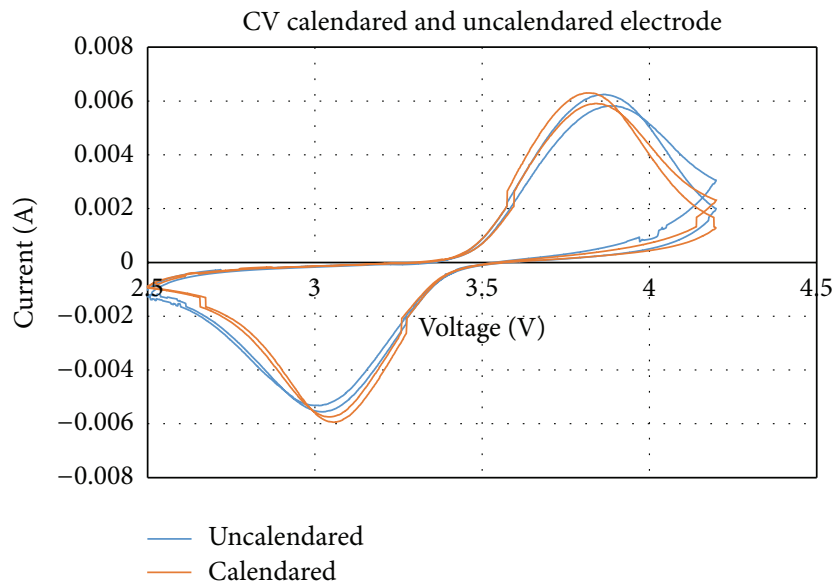

Figure 3: Cyclic voltammetry (CV) for both calendared and uncalendared electrodes.

$1 \mathrm{mV} / \mathrm{s}$; hence the wide voltage difference between the peaks as higher scan rates have been shown to affect the voltage difference and reversibility check.

3.3. Rate Test. The importance of calendaring on the performance of the battery is apparent in the rate test as shown in Figures 4 and 5 . The batteries were cycled at different $C$-rates, and the uncalendared electrode has a capacity of $120,100,86$, 55 , and $10 \mathrm{mAh} / \mathrm{g}$ at $C / 10, C / 5,1 C, 3 C$, and $5 C$, respectively,
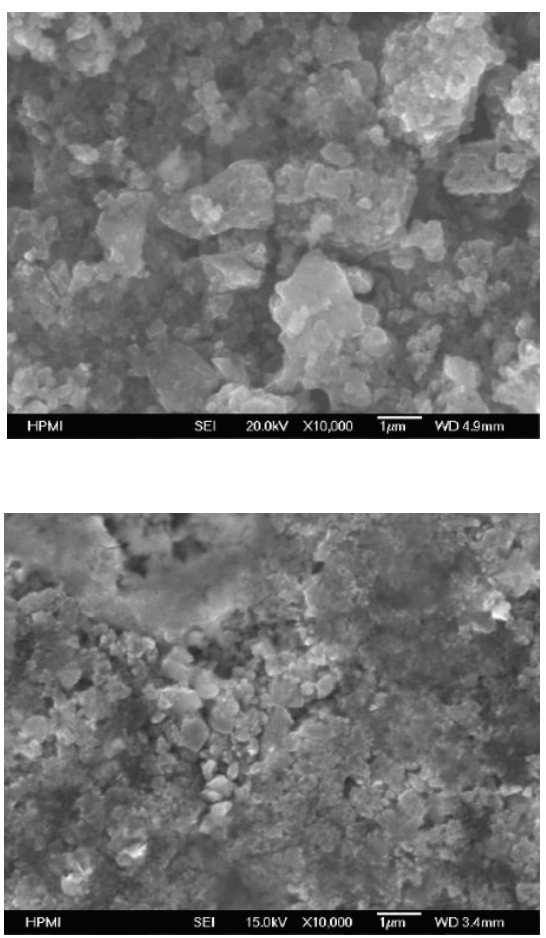


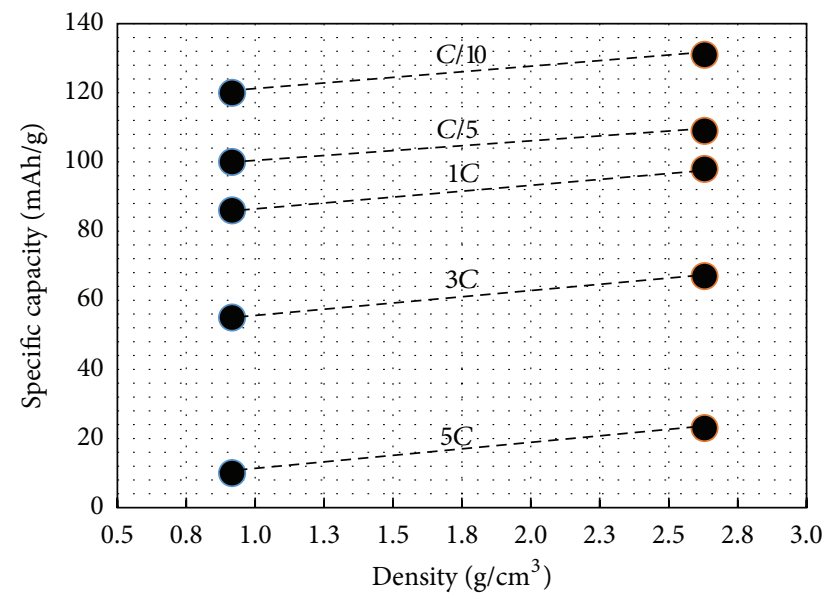

FIgURE 6: Discharge capacity for various electrode densities and $C$ rates.

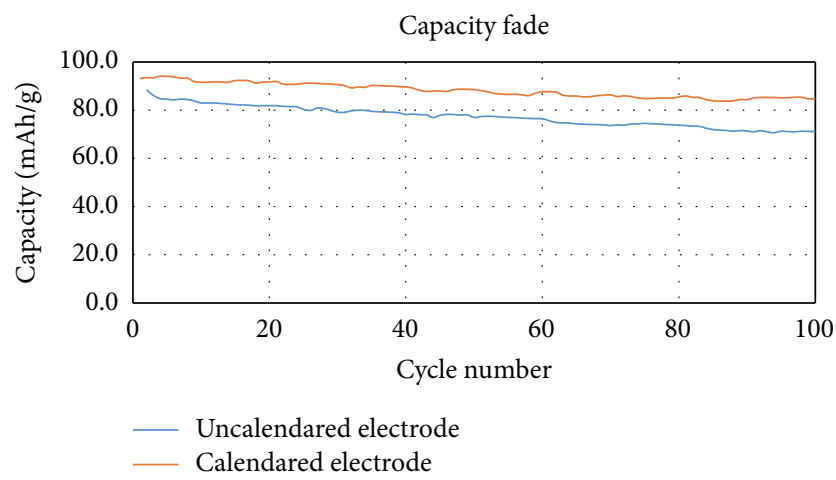

FIgURE 7: Capacity fade of calendared and uncalendared electrodes at $1 C$ for 100 cycles.

while the calendared electrode has a capacity of $131,109,98$, 67 , and $23 \mathrm{mAh} / \mathrm{g}$ at $C / 10, C / 5,1 C, 3 C$, and $5 C$, respectively. At $C / 10$ and $5 C$, the capacity is increased by about $9.17 \%$ and $130 \%$, respectively, by the calendaring process which implies that the importance of calendaring is prominent at higher charging and discharge rates [18].

Figure 6 shows the specific capacity at various $C$-rates and electrode densities. The results show improved kinetic and rate capability for electrodes with higher densities (i.e., calendared electrodes), and they are consistent with results that have been reported by previous research groups which have shown a reduced internal impedance of the electrode after densification. An investigation of internal electrode impedance was also performed using AC impedance (EIS), and the results are presented and discussed later in this work.

3.4. Capacity Fade. The graph of capacity against cycle number in Figure 7 shows the trend of capacity fade with time. The uncalendared and calendared electrode batteries were charged and discharged at $1 C$ for 100 cycles. The discharge capacity reduced significantly with similar slope for both calendared and uncalendared electrodes. The calendared and uncalendared electrode had a capacity of $95 \mathrm{mAh} / \mathrm{g}$ and

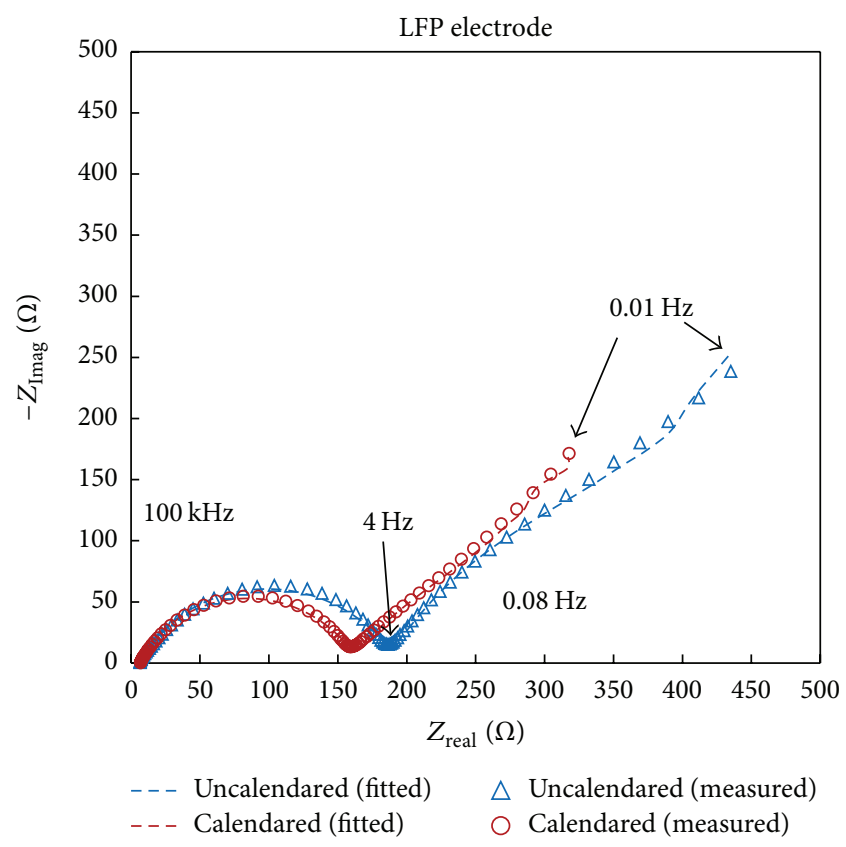

FIgURE 8: Measured EIS data with fitted results for uncalendared and calendared electrodes.

$85 \mathrm{mAh} / \mathrm{g}$, respectively, after the first cycle, and a capacity of $86 \mathrm{mAh} / \mathrm{g}$ and $71 \mathrm{mAh} / \mathrm{g}$ after the 100th cycle. Observing the capacity fade with cycle number, there is significant advantage shown by the calendared electrode over the uncalendared electrode.

3.5. Electrochemical Impedance Spectroscopy (EIS). To investigate the dependency of charge transfer kinetics on calendaring, EIS was collected on freshly made electrodes at room temperature by applying AC potential of $10 \mathrm{mV}$ for both calendared and uncalendared cells. Figure 8 shows the EIS measurements from $100 \mathrm{KHz}$ to $0.01 \mathrm{~Hz}$ for both the calendared and uncalendared electrodes. The impedance spectra at $100 \mathrm{kHz}$ composed of a high frequency intercept on the real axis represents the total ohmic resistance of $6.6 \Omega$ which includes the contact resistance, electrolyte resistance, and lead contacts. The depressed semicircles in the midfrequency range of $100 \mathrm{KHz}$ to $0.08 \mathrm{~Hz}$ characterize the charge transfer kinetics at the interfaces.

The low frequency range below $0.08 \mathrm{~Hz}$ of the impedance spectra can be assigned to the solid state Warburg diffusion of lithium ions into the porous electrode [19]. This model, and its representation, has been well established and used by many researchers to describe the migration and diffusion of lithium ions in electrochemical cells [20-23]. Additionally, the depress semicircles in the high to midfrequency range $(100 \mathrm{KHz}$ to $4 \mathrm{~Hz})$ are indicative of the activation resistance at the electrode/electrolyte interface and the resistance at the electrode/collector resistance $[16,17$, 24]. The calendared electrode clearly exhibited lower charge transfer resistance compared to the uncalendared electrode. Also, the depressed semicircle in the middle-low frequency range $(4 \mathrm{~Hz}$ to $0.08 \mathrm{~Hz})$ is diminished in the calendared 


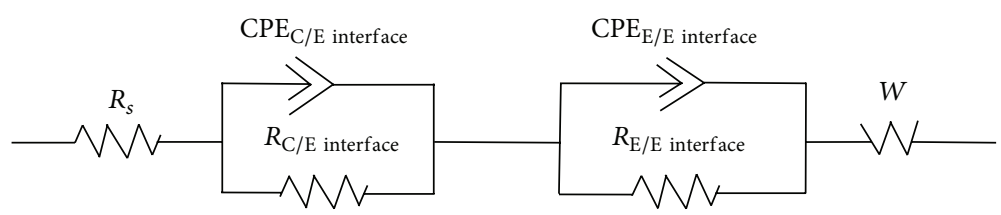

FIGURE 9: Equivalent circuit model for both electrodes.

electrode EIS spectrum as a result of calendaring. These changes imply that the interfacial kinetics of the electrodes are affected by calendaring. In the literature, the semicircle in the high frequency region initially was associated with the electrolyte/electrode interphase [25]. However, Gaberscek et al. in their work proved, contrary to initial suggestions, that the high frequency semicircle is dominated by current collector/electrode kinetics while the middle-low frequency semicircle represents the electrode/electrolyte interface [24]. The results of this work follow the latter case.

3.6. Equivalent Circuit Modeling. To further interpret results observed from the EIS response, ZView software was used to create an equivalent circuit model for the electrode as shown in Figure 8, and the model was fitted to the actual EIS profile as shown in Figure 9. The equivalent circuit is used to evaluate the impedance parameters of the electrode. $R_{s}$ represents the total ohmic resistance which includes the contact resistance, electrolyte resistance, and other electrical contacts. Constant phase elements (CPEs) are used to denote distributed capacitive behavior in electrodes made of fine nonhomogenous particles, influence of electrolyte and SEI interface, double layer capacitance, and other capacitive behavior that cannot be accurately represented using a capacitor. $R_{\mathrm{C} / \mathrm{E} \text { interface }}$ and $R_{\mathrm{E} / \mathrm{E} \text { interface }}$ signify the respective interface reaction resistance. A CPE is connected in parallel with a resistor to represent the charge transfer kinetics in the high-medium frequency range and the depressed semicircle in the medium to low frequency range. The Warburg impedance represents lithium diffusion in the electrode $[19,26]$.

The results generated from modeling are shown in Table 1. All elements were fitted with a high degree of accuracy with error not greater than $8 \%$. CPE- $T$ and CPE- $P$ are parameters that make up the impedance of constant phase elements expressed as

$$
Z=\frac{1}{T(j \omega)^{P}}(\Omega) .
$$

$\mathrm{W}-R, \mathrm{~W}-T, \mathrm{~W}-P$ are parameters that make up the impedance of the finite length Warburg elements expressed as

$$
Z=\frac{R \times \operatorname{coth}\left((j \times T \times \omega)^{P}\right)}{(j \times T \times \omega)^{P}}(\Omega) .
$$

The parameter $\omega$ is the angular frequency of the AC signal and $j=\sqrt{(-1)}$.

Observing the values in Table 1 for the various components of the equivalent circuit, the solution resistance $R_{s}$ is approximately equal for both electrodes indicating similar
TABLE 1: Equivalent circuit values of impedance fittings for the

\begin{tabular}{|c|c|c|}
\hline Circuit element & Calendared & Uncalendarec \\
\hline$R_{s}(\Omega)$ & 6.632 & 6.6 \\
\hline $\mathrm{W}-R(\Omega)$ & 758.9 & 839.6 \\
\hline $\left.\mathrm{W}-T(\operatorname{rad~S})^{-1}\right)$ & 114.3 & 105.1 \\
\hline $\mathrm{W}-\mathrm{P}$ (unitless) & 0.80523 & 0.70224 \\
\hline $\mathrm{CPE}_{\mathrm{E} / \mathrm{E} \text { interface }}-T\left(\mathrm{~F} \mathrm{~S}^{P-1} \mathrm{~cm}^{-2}\right)$ & 0.016147 & 0.015222 \\
\hline $\mathrm{CPE}_{\mathrm{E} / \mathrm{E} \text { interface }}-P$ (unitless) & 0.72089 & 0.75702 \\
\hline$R_{\mathrm{E} / \mathrm{E} \text { interface }}(\Omega)$ & 153.3 & 176.2 \\
\hline $\mathrm{CPE}_{\mathrm{C} / \mathrm{E} \text { interface }}-T\left(\mathrm{FS}^{P-1} \mathrm{~cm}^{-2}\right)$ & $2.4452 E-5$ & $2.4573 E-5$ \\
\hline $\mathrm{CPE}_{\mathrm{C} / \mathrm{E} \text { interface }}-P$ (unitless) & 0.76262 & 0.74231 \\
\hline$R_{\mathrm{C} / \mathrm{E} \text { interface }}(\Omega)$ & 157.8 & 182.4 \\
\hline
\end{tabular}
electrodes.

electrolyte and electrical resistance of about $6.6 \Omega$. This implies that both electrodes have exactly the same solution resistance. The values of Warburg impedance parameters vary for both electrodes as expected, since the thickness of the calendared electrode is reduced and has an effect on Warburg impedance $[12,26]$. The resistances of the interfacial layer is reduced from $176.2 \Omega$ to $153.3 \Omega$ for $R_{\mathrm{C} / \mathrm{E} \text { interface }}$ and

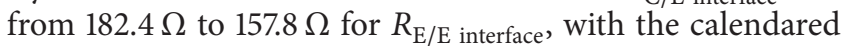
electrode having the smaller impedance for both layers. The reduction of $R_{\mathrm{E} / \mathrm{E} \text { interface }}$ is a result of increased interparticle contact between the LFP particles and carbon particles while $R_{\mathrm{C} / \mathrm{E} \text { interface }}$ is reduced due to better particle/current collector contact in the electrode [27]. $\mathrm{CPE}_{\mathrm{E} / \mathrm{E} \text { interface }}$ and

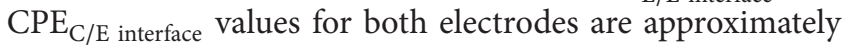
equal indicating that the capacitive behavior of the interface is not greatly affected by calendaring which implies little or no change to the effective surface area as a result of calendaring. Values of CPE- $P$ range from 1 to -1 , with 1 indicative of a capacitor, 0 a resistor, and -1 and inductor. With CPE- $P$ values around 0.7 , the interface exhibits distributive capacitive behavior for both electrodes.

3.7. Analyzing the Electrode/Collector Interface. The activation resistance at the electrode/electrolyte interface is governed by the Butler-Volmer equation $[28,29]$ as

$$
\begin{aligned}
I= & A i_{o}\left\{\exp \left[\frac{(1-\alpha) n F}{R T}\left(E-E_{\text {eq }}\right)\right]\right. \\
& \left.-\exp \left[-\frac{(\alpha) n F}{R T}\left(E-E_{\text {eq }}\right)\right]\right\}(\mathrm{mA}),
\end{aligned}
$$

where $A$ is the electrode active surface area, $i_{o}$ is the exchange current, $\alpha$ is the charge transfer coefficient, $n$ is the number of electrons involved in the reaction, $F$ is Faraday's constant, $R$ is 
the universal gas constant, $T$ is temperature, $E$ is the electrode potential, and $E_{\mathrm{eq}}$ is equilibrium potential.

A pure $\mathrm{LiFePO}_{4}$ electrode is a semiconductor with a band gap of $0.3 \mathrm{eV}$. The electrode/collector interface between the $\mathrm{LiFePO}_{4} /$ carbon/binder bulk and the metal aluminum collector should obey laws of an ohmic contact [30]. Doped or carbon coated $\mathrm{LiFePO}_{4}$ in contact with aluminum, according to theories of semiconductor materials, exhibits ohmic contact resistance described as

$$
R_{\text {contact }}=\frac{d V_{\text {contact }}}{d I}=\frac{\rho_{c}}{A}(\Omega),
$$

where $\rho_{c}$ is the specific contact resistivity and $A$ is the contact area. Since a very small voltage is required to drive current through the contact area, the specific contact resistivity can be defined as

$$
\lim _{v \rightarrow 0}\left(\frac{d V_{\text {contact }}}{d J}\right)\left(\Omega \mathrm{cm}^{2}\right),
$$

where $J$ is the current density and can be defined as

$$
J=\frac{V_{\text {metal }}-V_{\text {semiconductor }}}{\rho_{c}}\left(\mathrm{~mA} \mathrm{~cm}^{-2}\right) .
$$

In a simplified form, resistance can be said to obey Ohm's law and is defined as

$$
R=\rho \frac{l}{A}(\Omega),
$$

where the resistance is inversely proportional to the contact area. Therefore as the surface area increases, the resistance decreases.

The equations in this section clearly show that there is a direct relationship between the contact resistance, current density, and contact area. It is also shown that for a doped/carbon coated semiconductor, the contact resistance is dependent on contact area. Therefore the reduction in resistance exhibited at the electrode/current collector interface is a result of increased contact area. An increase in contact area therefore results in a decrease in resistance as shown by Wang et al. in their work comparing performance of a $\mathrm{LiFePO}_{4}$ battery coated on a $3 \mathrm{D}$ porous current collector and on an aluminum foil current collector [18].

Since the ohmic contact resistance, Warburg impedance, and activation resistance are in series, using the law of current resistances in series as shown in Figure 10, current through the electrode/electrolyte interface and current at the electrode/current collector interface are equal. This implies that

$$
I_{\text {ohmic contact }}=I_{\text {Butler-Volmer }}(\mathrm{mA}) \text {. }
$$

A decrease in resistance due to calendaring should result in decreases in activation and ohmic polarization. This can be observed in the charge/discharge profile and is more prominent at higher discharge rates as shown in Figure 11. Since the charge/discharge current is the same and the resistance is different, the effect of the change in resistance is in the voltage or over potential.

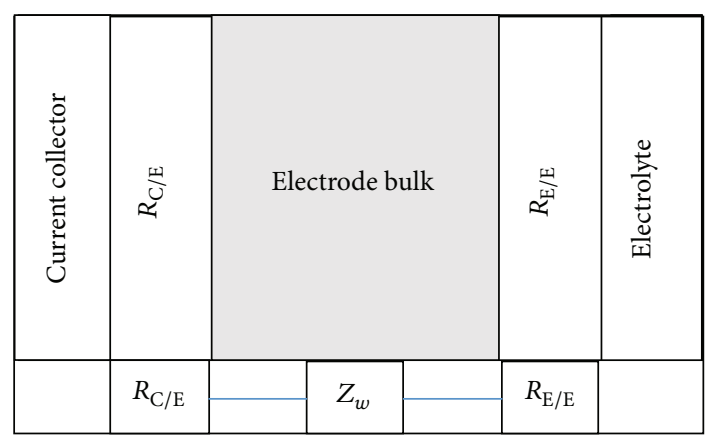

FIGURE 10: Block diagram showing the various impedances of the electrode. Ohmic contact resistance, Warburg impedance, and activation resistance are in series.

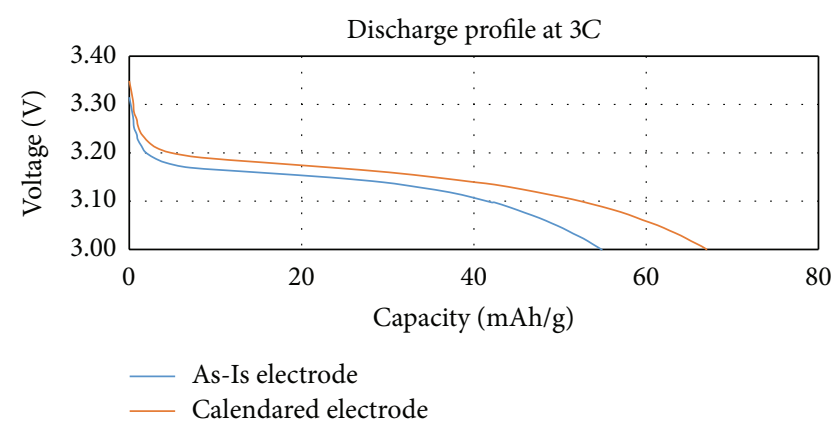

FIGURE 11: Discharge capacity of uncalendared and calendared electrodes at $3 C$.

\section{Conclusion}

Using solid state processes, $\mathrm{Li}_{2} \mathrm{CO}_{3}, \mathrm{NH}_{4} \mathrm{H}_{2} \mathrm{PO}_{4}$, and $\mathrm{FeC}_{2} \mathrm{O}_{4} \cdot \mathrm{H}_{2} \mathrm{O}$ and $\mathrm{C}_{12} \mathrm{H}_{22} \mathrm{O}_{11}$ precursor materials were used to synthesis olivine structure $\mathrm{LiFePO}_{4}$. Calendared and uncalendared electrodes were characterized and analyzed to study the effect of calendaring on the performance of the battery and the role of calendaring in optimizing LFP battery. SEM, EIS, CV, rate test, and capacity fade test were performed on both the calendared and uncalendared electrode and the results were compared. The higher density (calendared) electrode clearly exhibited better electrochemical performances such as lower impedance and higher capacity of about $130 \mathrm{mAh} / \mathrm{g}$ at $0.1 \mathrm{C}$ compared to a discharge capacity of $120 \mathrm{mAh} / \mathrm{g}$ at $0.1 \mathrm{C}$ for the uncalendared electrode. It was concluded using parameters obtained from equivalent circuit modeling that the added performance is due to the increased ohmic contact area at the electrode/current collector interface.

\section{Competing Interests}

The authors declare that they have no competing interests.

\section{References}

[1] J. Barker, M. Y. Saidi, and J. L. Swoyer, "Lithium iron(II) phospho-olivines prepared by a novel carbothermal reduction 
method," Electrochemical and Solid-State Letters, vol. 6, no. 3, pp. A53-A55, 2003.

[2] J. Hu, J. Xie, X. Zhao et al., "Doping effects on electronic conductivity and electrochemical performance of LiFePO4," Journal of Materials Science \& Technology, vol. 25, no. 3, pp. 405409, 2009.

[3] S. Ferrari, R. L. Lavall, D. Capsoni et al., "Influence of particle size and crystal orientation on the electrochemical behavior of carbon-coated $\mathrm{LiFePO}_{4}$," The Journal of Physical Chemistry C, vol. 114, no. 29, pp. 12598-12603, 2010.

[4] M. Gaberscek, R. Dominko, and J. Jamnik, "Is small particle size more important than carbon coating? An example study on $\mathrm{LiFePO}_{4}$ cathodes," Electrochemistry Communications, vol. 9, no. 12, pp. 2778-2783, 2007.

[5] D. Zhang, R. Cai, Y. Zhou, Z. Shao, X.-Z. Liao, and Z.-F. $\mathrm{Ma}$, "Effect of milling method and time on the properties and electrochemical performance of $\mathrm{LiFePO}_{4} / \mathrm{C}$ composites prepared by ball milling and thermal treatment," Electrochimica Acta, vol. 55, no. 8, pp. 2653-2661, 2010.

[6] S. Moon, P. Muralidharan, and D. K. Kim, "Carbon coating by high-energy milling and electrochemical properties of LiMnPO 4 obtained in polyol process," Ceramics International, vol. 38, no. 1, pp. S471-S475, 2012.

[7] Z. Bakenov and I. Taniguchi, "Physical and electrochemical properties of $\mathrm{LiMnPO}_{4} / \mathrm{C}$ composite cathode prepared with different conductive carbons," Journal of Power Sources, vol. 195, no. 21, pp. 7445-7451, 2010

[8] F. Wang, J. Yang, P. Gao, Y. Nuli, and J. Wang, "Morphology regulation and carbon coating of $\mathrm{LiMnPO}_{4}$ cathode material for enhanced electrochemical performance," Journal of Power Sources, vol. 196, no. 23, pp. 10258-10262, 2011.

[9] S.-K. Zhong, Y. Wang, J.-Q. Liu, and J. Wang, "Synthesis of $\mathrm{LiMnPO}_{4} / \mathrm{C}$ composite material for lithium ion batteries by solgel method," Transactions of Nonferrous Metals Society of China, vol. 22, no. 10, pp. 2535-2540, 2012.

[10] G. Cheng, P. Zuo, L. Wang et al., "High-performance carboncoated $\mathrm{LiMnPO}_{4}$ nanocomposites by facile two-step solidstate synthesis for lithium-ion battery," Journal of Solid State Electrochemistry, vol. 19, no. 1, pp. 281-288, 2015.

[11] H. Zheng, G. Liu, X. Song, and V. Battaglia, " $\mathrm{Li}\left[\mathrm{Ni}_{1 / 3} \mathrm{Mn}_{1 / 3} \mathrm{Co}_{1 / 3}\right] \mathrm{O}_{2}$-based electrodes for PHEV applications: an optimization," ECS Transactions, vol. 11, no. 32, pp. 1-9, 2008.

[12] H. Zheng, J. Li, X. Song, G. Liu, and V. S. Battaglia, "A comprehensive understanding of electrode thickness effects on the electrochemical performances of Li-ion battery cathodes," Electrochimica Acta, vol. 71, pp. 258-265, 2012.

[13] I. V. Thorat, T. Joshi, K. Zaghib, J. N. Harb, and D. R. Wheeler, "Understanding rate-limiting mechanisms in $\mathrm{LiFePO}_{4}$ cathodes for Li-ion batteries," Journal of the Electrochemical Society, vol. 158, no. 11, pp. A1185-A1193, 2011.

[14] J. Shim and K. A. Striebel, "Effect of electrode density on cycle performance and irreversible capacity loss for natural graphite anode in lithium-ion batteries," Journal of Power Sources, vol. 119-121, pp. 934-937, 2003.

[15] A. Van Bommel and R. Divigalpitiya, "Effect of calendering $\mathrm{LiFePO}_{4}$ electrodes," Journal of the Electrochemical Society, vol. 159, no. 11, pp. A1791-A1795, 2012.

[16] J. Illig, T. Chrobak, D. Klotz, and E. Ivers-Tiffée, "Evaluation of the rate determining processes for $\mathrm{LiFePO}_{4}$ as cathode material in lithium-ion-batteries," ECS Transactions, vol. 33, no. 29, pp. 3-15, 2011.
[17] J. Illig, M. Ender, T. Chrobak, J. P. Schmidt, D. Klotz, and E. Ivers-Tiffée, "Separation of charge transfer and contact resistance in $\mathrm{LiFePO}_{4}$-cathodes by impedance modeling," Journal of the Electrochemical Society, vol. 159, no. 7, pp. A952-A960, 2012.

[18] Q. Wang, D. Wang, and B. Wang, "Preparation and electrochemical performance of $\mathrm{LiFePO}_{4}$-based electrode using threedimensional porous current collector," International Journal of Electrochemical Science, vol. 7, pp. 8753-8760, 2012.

[19] X.-Z. Liao, Z.-F. Ma, Y.-S. He, X.-M. Zhang, L. Wang, and Y. Jiang, "Electrochemical behavior of $\mathrm{LiFePO}_{4} / \mathrm{C}$ cathode material for rechargeable lithium batteries," Journal of the Electrochemical Society, vol. 152, no. 10, pp. A1969-A1973, 2005.

[20] C. Wang and J. Hong, "Ionic/electronic conducting characteristics of $\mathrm{LiFePO}_{4}$ cathode materials," Electrochemical and SolidState Letters, vol. 10, no. 3, pp. A65-A69, 2007.

[21] W. Lu, A. Jansen, D. Dees, and G. Henriksen, "Olivine electrode engineering impact on the electrochemical performance of lithium-ion batteries," Journal of Materials Research, vol. 25, no. 8, pp. 1656-1660, 2010.

[22] Y.-R. Zhu, Y. Xie, R.-S. Zhu et al., "Kinetic study on $\mathrm{LiFePO}_{4}$ positive electrode material of lithium-ion battery," Ionics, vol. 17, no. 5, pp. 437-441, 2011.

[23] F. Gao and Z. Tang, "Kinetic behavior of $\mathrm{LiFePO}_{4} / \mathrm{C}$ cathode material for lithium-ion batteries," Electrochimica Acta, vol. 53, no. 15, pp. 5071-5075, 2008.

[24] M. Gaberscek, J. Moskon, B. Erjavec, R. Dominko, and J. Jamnik, "The importance of interphase contacts in Li ion electrodes: the meaning of the high-frequency impedance arc," Electrochemical and Solid-State Letters, vol. 11, no. 10, pp. A170A174, 2008.

[25] F. Orsini, M. Dollé, and J.-M. Tarascon, "Impedance study of the Li /electrolyte interface upon cycling," Solid State Ionics, vol. 135, no. 1-4, pp. 213-221, 2000.

[26] M. Greenleaf, Physical Based Modeling and Simulation of LiFePO4 Secondary Batteries, 2010.

[27] H. Zheng, L. Tan, G. Liu, X. Song, and V. S. Battaglia, "Calendering effects on the physical and electrochemical properties of $\mathrm{Li}\left[\mathrm{Ni}_{1 / 3} \mathrm{Mn}_{1 / 3} \mathrm{Co}_{1 / 3}\right] \mathrm{O}_{2}$ cathode," Journal of Power Sources, vol. 208, pp. 52-57, 2012.

[28] A. V. Virkar, J. Chen, C. W. Tanner, and J.-W. Kim, "Role of electrode microstructure on activation and concentration polarizations in solid oxide fuel cells," Solid State Ionics, vol. 131, no. 1-2, pp. 189-198, 2000.

[29] R. F. Mann, J. C. Amphlett, B. A. Peppley, and C. P. Thurgood, "Application of Butler-Volmer equations in the modelling of activation polarization for PEM fuel cells," Journal of Power Sources, vol. 161, no. 2, pp. 775-781, 2006.

[30] Q. C. Zhuang, S. G. Sun, S. D. Xu, X. Y. Qiu, and Y. H. Qiang, "Diagnosis of electrochemical impedance spectroscopy in lithium-ion batteries," in Lithium Ion Batteries-New Developments, INTECH, Rijeka, Croatia, 2012. 

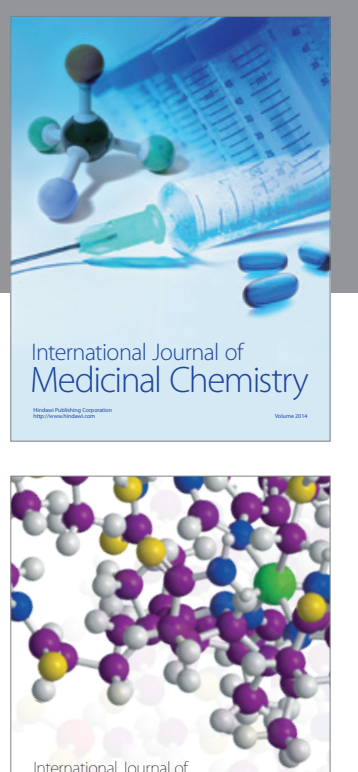

Carbohydrate Chemistry

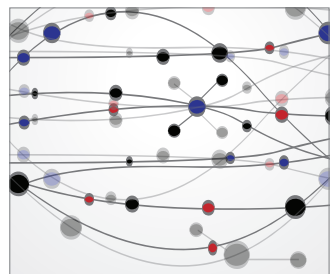

The Scientific World Journal
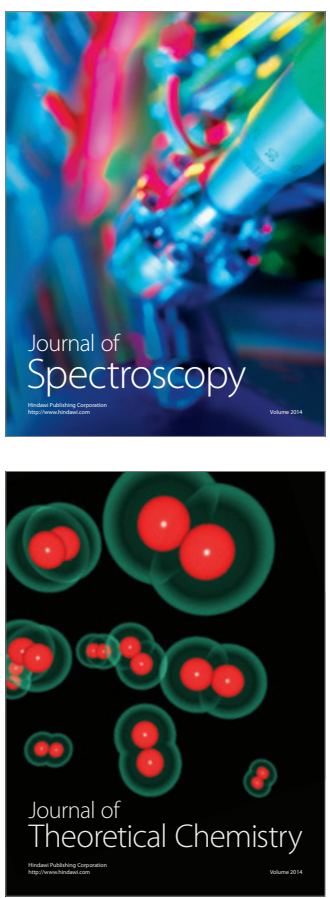
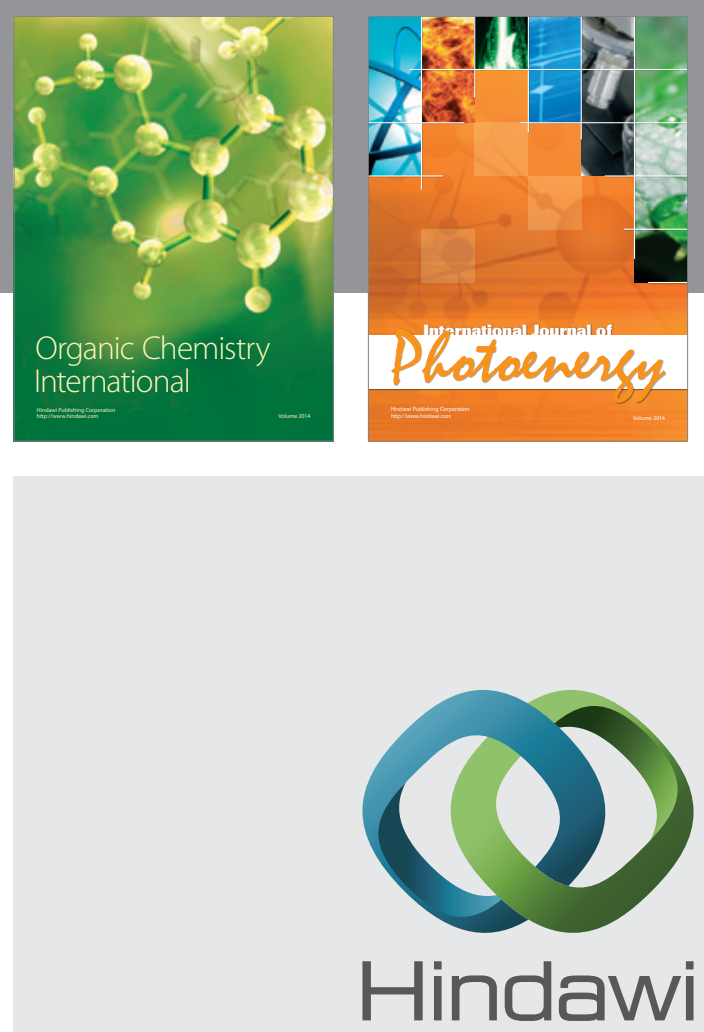

Submit your manuscripts at

http://www.hindawi.com

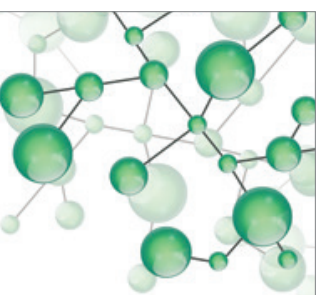

International Journal of

Inorganic Chemistry

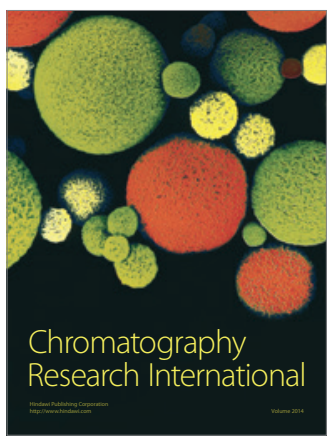

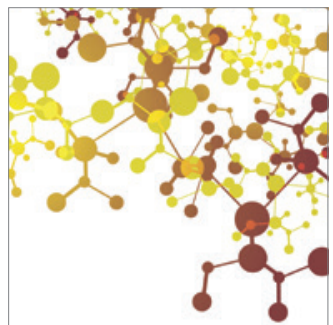

Applied Chemistry
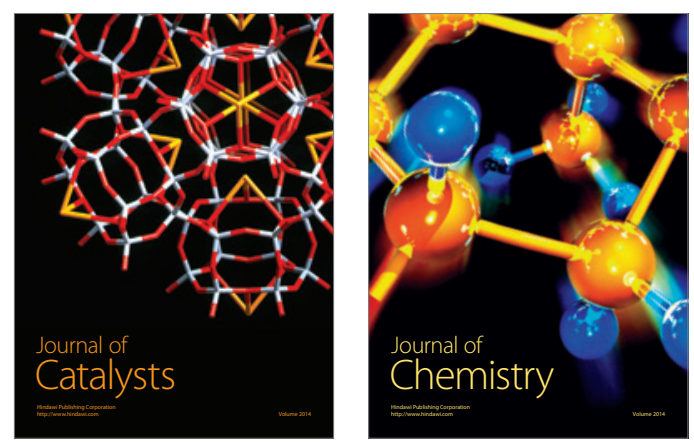
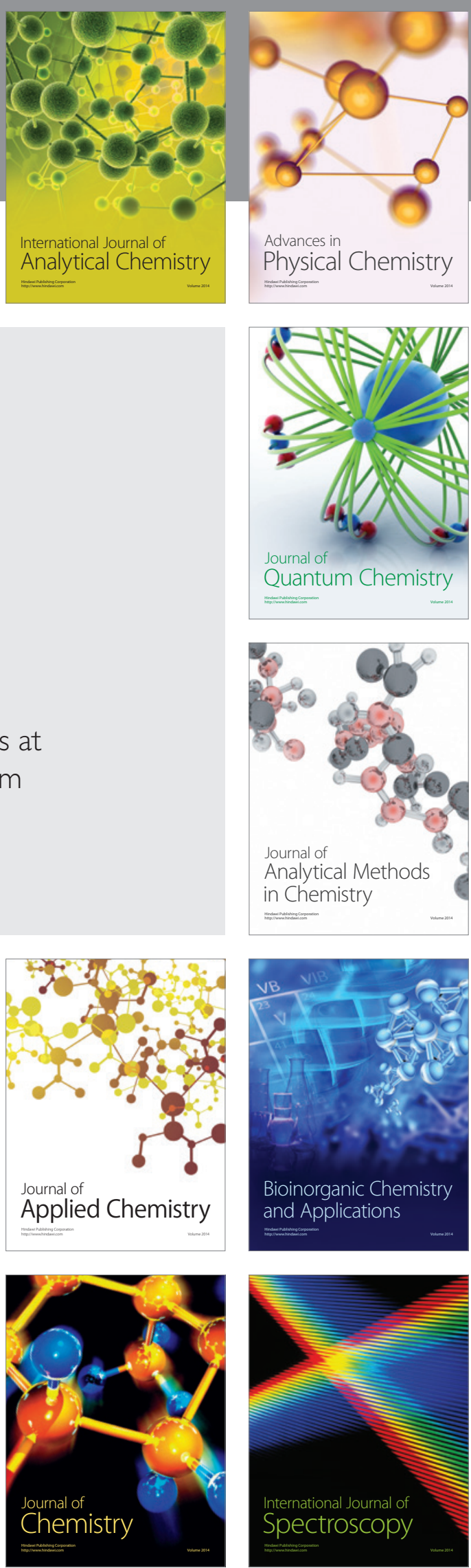